\title{
Experimental and numerical study on the influence of the laser hybrid parameters in partial penetration welding on the solidification cracking in the weld root
}

\author{
Nasim Bakir ${ }^{1} \cdot$ Ömer Üstündağ ${ }^{1} \cdot$ Andrey Gumenyuk $^{1,2}$ (D) Michael Rethmeier ${ }^{1,2,3}$
}

Received: 22 October 2019 / Accepted: 1 January 2020 /Published online: 27 January 2020

(C) The Author(s) 2020

\begin{abstract}
The aim of the present study is to investigate the influence of the laser hybrid welding parameters on the solidification cracks in the weld root for partial penetration welding. Welding trials were performed on thick-walled high-strength steels of grade S690QL under the same critical restraint intensity, with a variation of the welding velocity, wire feeding rate, and the focal position of the laser beam. It was ascertained that the welding velocity has a high impact on the solidification cracking phenomenon. A decrease in the welding speed leads to a reduction of the number of cracks in the weld root. The arc power has also a slight influence on the solidification cracking, while the change of the focal position of the laser beam shows also a remarkable effect. Besides, numerical simulation was performed to understand the thermomechanical behavior of the welds for different welding parameters to assist the interpretation of the experimental results.
\end{abstract}

Keywords Laser hybrid welding $\cdot$ Solidification cracking $\cdot$ Thick-walled steels $\cdot$ Partial penetration $\cdot$ High-power laser beam

\section{Introduction}

In recent years, laser-based welding processes such as laser beam welding (LBW) or hybrid laser-arc welding (HLAW) became important welding processes in welding of thick materials. The HLAW provides many advantages over conventional arc-based welding processes such as gas metal arc welding (GMAW) or submerged arc welding (SAW) and pure LBW. The coupling of the laser beam and arc welding in one process zone has been presented at the end of the 1970s [1]. The high energy density of the laser beam ensures a high

Recommended for publication by Commission IV - Power Beam Processes

Andrey Gumenyuk

andrey.gumenyuk@bam.de

1 Bundesanstalt für Materialforschung und -prüfung, Unter den Eichen, 8712205 Berlin, Germany

2 Fraunhofer Institute for Production Systems and Design Techology, Pascalstraße 8-9, 10587 Berlin, Germany

3 Institute of Machine Tools and Factory Management, Technische Universität Berlin, Pascalstraße 8-9, 10587 Berlin, Germany penetration depth and high welding speeds and significantly decreases the welding distortion due to reduced heat input, whereas LBW joints tend to have high cooling rates and a decrease in the toughness of the welded joints. A special focus on edge preparation is also necessary since the LBW is sensitive to manufacturing tolerances such as gaps and misalignment of edges. The additional supplied energy of the arc welding process and the filler wire serve to overcome these disadvantages [2]. Above all, the HLAW process prevailed in some industrial applications such as the shipbuilding industry in the 2000s [3]. Panels with dimensions up to $20 \mathrm{~m} \times 20 \mathrm{~m}$ are welded with the HLAW with reduced thermal distortion, which was mainly the driving force of the use of this technology in shipbuilding. This also reduces reworking time necessary after welding such as straightening works. Considering that the total weld joint length for a passenger ship can be up to $400 \mathrm{~km}$, costs for straightening are estimated from 15 to $30 \%$ $[4,5]$. The thickness of the welded material is as far as $15 \mathrm{~mm}$. Although there are already laser systems with output power up to $100 \mathrm{~kW}$ in the market, their application for welding of thick sections is still far from real industrial scale and remains restricted to a few cases mostly where the thickness of the parts does not exceed $15 \mathrm{~mm}$ due to certain technological limitations. One of the limiting factors is the formation of 


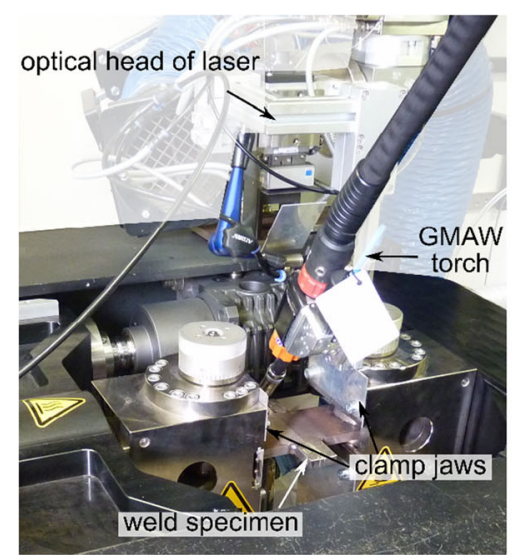

Fig. 1 Experimental setup

imperfections of the weld joint such as cracks. Several studies and theories were performed to investigate the cause of the formation of solidification cracks and to overcome this limitation.

Solidification crack formation is influenced by the interaction of mechanical, thermal, and metallurgical factors during welding [6]. Apblett and Pellini [7] hypothesize that solidification cracking occurs due to a critical strain at a temperature slightly above the solidus temperature. A thin film of liquid is present between the dendrite structures, which leads to the formation of hot cracks if the highly localized strains in the liquid films exceed their critical limits. This liquid film contains impurities, low-melting eutectic, and iron sulfide (FeS), which has a solidus temperature of $988^{\circ} \mathrm{C}$ [8]. Prokhorov [9-11] found that cracks are formed in a temperature range between the solidus temperature $T_{\mathrm{S}}$ and the liquidus temperature $T_{\mathrm{L}}$, the so-called brittle temperature range (BTR). Hot cracks will occur if the strain during solidification exceeds the deformation capacity. Studies by Zacharia et al. [12] showed a functional relationship between the resulting stresses in the weld and the formation of hot cracking, which was presented via in situ observations and numerical simulations. A metallurgical model based on the ratio of the cooling-related volume deformation, the so-called rate of shrinkage (ROS) and the rate of feeding (ROF) for closing the cavity, was represented by Feurer [13]. Hot cracks are formed if the shrinkage rate exceeds the feeding rate.

The weld shape geometry plays also a significant role in the formation of solidification cracks. A large depth-towidth ratio often leads to the formation of centerline

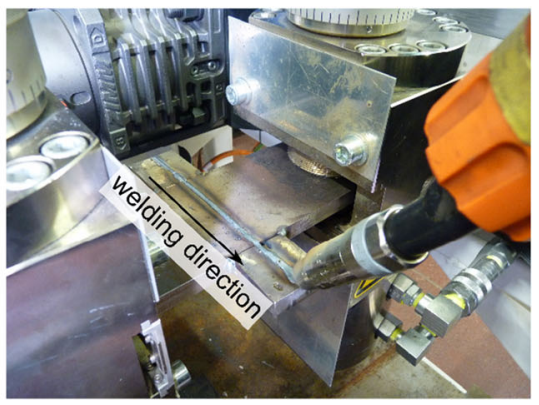

cracks for high-power laser-based welding processes. The center of the weld solidifies at last and therefore contains large columnar-shaped grains, which impinge on each other. Thereby, voids between the grains arise, which cannot be filled with the molten filler being added from above. Numerical and experimental analyses by Bakir et al. [14] show that a bulging region is created in the centerline due to the Marangoni vortex on the surfaces. Solidification cracks are expected in the bulging region. This phenomenon is more frequent for partial penetration welds. Gebhardt et al. [15, 16] show that cracks are formed close to the weld root. As the wire feed speed increased, the number of cracks could be reduced. Growth in penetration depth due to an increase of the laser power showed the opposite effect. The welding speed, which was variated in a range between 1.7 and $3.2 \mathrm{~m} \mathrm{~min}^{-1}$, showed no significant influence on the crack number. Schaefer et al. [17] demonstrated that crack formation can be eliminated for partial penetration HLAW using a higher optical magnification of 2.67. They also showed that the focal position of the laser beam affected the melt flow during laser welding of steel, the keyhole shape, and the weld pool geometry [18]. However, these modifications of the melt flow were mainly on the upper half of the weld pool.

This study primarily attempts to investigate the influence of HLAW parameters on the solidification crack formation for partial penetration welds under defined restraint conditions. Furthermore, a numerical model based on the thermomechanical analyses is developed to understand the

Table 1 Chemical composition of the materials used (shown in wt\%)

\begin{tabular}{lllllllllll}
\hline & $\mathrm{C}$ & $\mathrm{Si}$ & $\mathrm{Mn}$ & $\mathrm{P}$ & $\mathrm{S}$ & $\mathrm{Cr}$ & $\mathrm{Ni}$ & $\mathrm{Mo}$ & $\mathrm{Cu}$ & $\mathrm{Fe}$ \\
\hline S690QL & 0.186 & 0.34 & 1.43 & 0.013 & 0.002 & 0.86 & - & 0.35 & 0.016 & bal. \\
G 79 5 M21 Mn4Ni1,5CrMo & 0.09 & 0.71 & 1.73 & - & - & 0.27 & 1.86 & 0.54 & - & bal. \\
\hline
\end{tabular}


Table 2 Hybrid laser-arc welding parameters used for the experiments

\begin{tabular}{llll}
\hline$v_{\mathrm{w}}$ in $\mathrm{m} \mathrm{min}^{-1}$ & $P_{\mathrm{L}}$ in $\mathrm{kW}$ & $v_{\text {wire }}$ in $\mathrm{m} \mathrm{min}^{-1}$ & $z_{\mathrm{f}}$ in $\mathrm{mm}$ \\
\hline $1-2.5$ & $7-12.5$ & $6.7-10.7$ & -3 \\
\hline
\end{tabular}

influence of welding parameters which show experimentally impact on the crack formation.

\section{Experimental setup}

The high-power Yb:YAG thin disk laser TruDisk 16002 with a maximum output power of $16 \mathrm{~kW}$, an emission wavelength of $1030 \mathrm{~nm}$, and a beam parameter product of $8 \mathrm{~mm} \times \mathrm{mrad}$ was used as the laser beam source. The laser radiation was transmitted through an optical fiber with a core diameter of $200 \mu \mathrm{m}$. With an optical magnification of 2.1, the spot focus diameter of the laser beam was $0.42 \mathrm{~mm}$. A welding machine Quinto GLC 603 with a maximum output power of $600 \mathrm{~A}$ served as an arc welding power source. The laser axis was positioned $90^{\circ}$ to the weld specimen surface, and the GMAW torch was tilted $30^{\circ}$ relative to the laser axis. The experiments were carried out with an arc leading orientation and a distance of $4 \mathrm{~mm}$ between the two heat sources. The wire stick-out was kept at $18 \mathrm{~mm}$.

The Controlled Tensile Weldability test (CTW) $[6,19]$ was used for all experiments under a defined restraint intensity of $20 \mathrm{kN}(\mathrm{mm} \mathrm{mm})^{-1}$. A set of experiments was performed in advance with a variation of the restraint intensity between $3.5 \mathrm{kN}(\mathrm{mm} \mathrm{mm})^{-1}$ and $80 \mathrm{kN}(\mathrm{mm} \mathrm{mm})^{-1}$. An increase in the number of solidification cracks was ascertained at $20 \mathrm{kN}$ $(\mathrm{mm} \mathrm{mm})^{-1}$ that is why it was determined as a critical restraint intensity for crack formation for this study.

The loading direction was perpendicular to the welding direction. Therefore, the plates were clamped between two jaws. The experimental setup is shown in Fig. 1.

The welding experiments were conducted on 15 -mm-thick plates of S690QL grade high-strength steel in a butt joint configuration. A solid wire Union X85 (G 795 M21 Mn4Ni1,5CrMo according to EN ISO 16834-A) with a diameter of $1.2 \mathrm{~mm}$ was used as a filler wire. The welds were performed under the gas shielding. The gas mixture consisted of $82 \% \mathrm{Ar}$ and $18 \% \mathrm{CO}_{2}$. The gas flow rate was $201 \mathrm{~min}^{-1}$.

Table 3 3-level factorial design: the values of the varied welding parameters
Table 4 3-level factorial design: the welding parameter combination

Table 1 shows the chemical composition of the materials used. The chemical composition of the base material and filler material were measured by OES spectral analyses.

A series of experiments were designed with a variation of the welding speed $\left(v_{\mathrm{w}}\right)$, the wire feeding rate $\left(v_{\text {wire }}\right)$, the focal position of the laser beam $\left(z_{\mathrm{f}}\right)$, and the laser power $\left(P_{\mathrm{L}}\right)$. The laser power was adjusted to ensure the same penetration depth for each welding speed for better comparability. The welding parameters are presented in Table 2.

The evaluation is carried out by means of X-ray examinations and metallographic examinations (preparation of macro sections).

The influence of the focal position on the crack formation was investigated depending on the welding speed. To carry out experiments, a 3-level factorial design with two parameters (factors) was adopted. In this experiment, the wire feeding rate and laser power were constant and have a value of $8 \mathrm{~m} \mathrm{~min}^{-1}$ and $7 \mathrm{~kW}$, respectively. In Table 3, the used factor levels for the welding speed and the focal position are listed. Table 4 shows the 3-level factorial design and the welding parameter combination.

In this design of experiments (DoE), the center value of the focal position was $-3 \mathrm{~mm}$ and for the welding speed $1.5 \mathrm{~m} \mathrm{~min}^{-1}$.

\section{Numerical model}

A three-dimensional model was employed to perform the thermomechanical simulation. The stress-strain diagram was taken from the SYSWELD material database [20]. The data was supplied for S355J2G3 and scaled for the S690QL. The thermophysical material properties were kept the same. The material was assumed to follow an elastoplastic law with isotropic hardening behavior (von Mises plasticity model). Phase transformation is also considered in the model. The clamping has been replaced in the model with three-dimensional spring elements that have a similar stiffness like the CTW test. This simplification was also used by $[15,21]$. Figure 2 shows the 


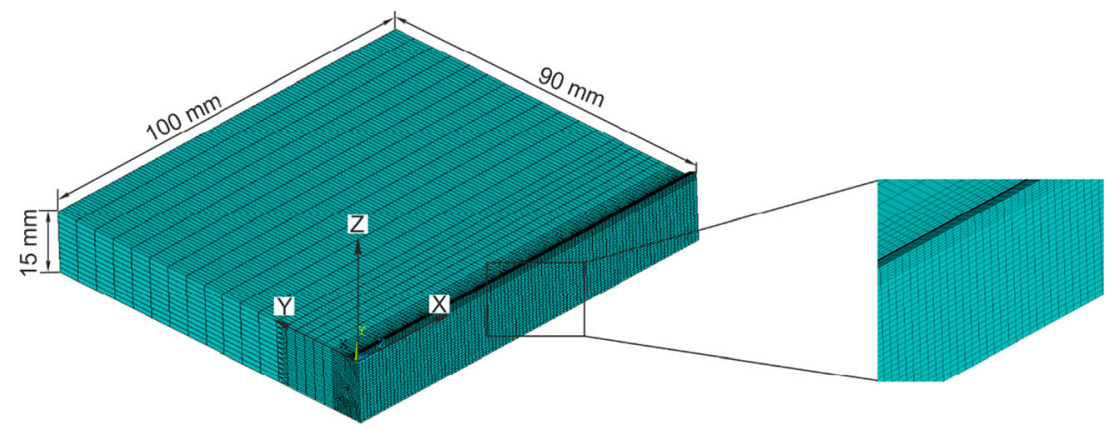

Fig. 2 Finite element mesh and model dimension

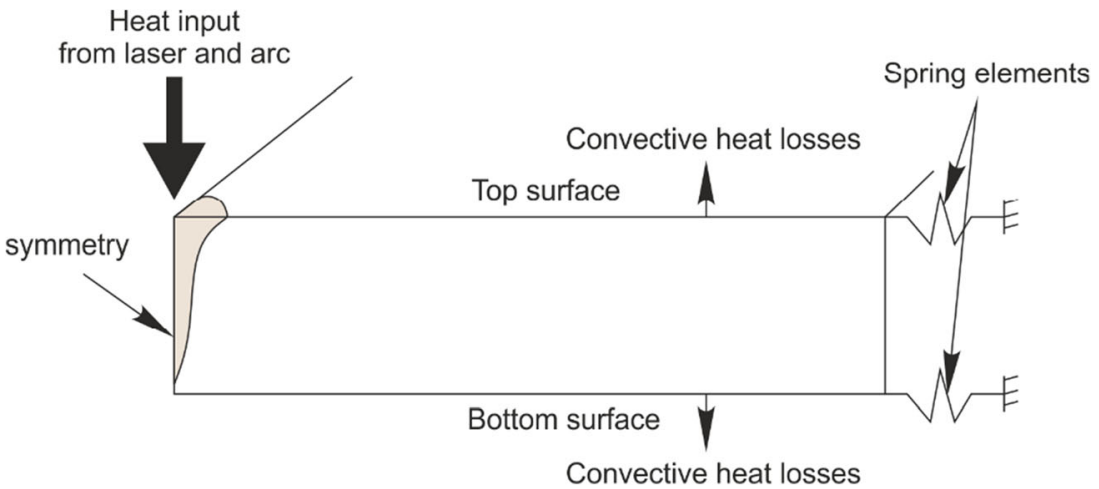

Fig. 3 Schematic presentation of the model with applied boundary condition

dimensions of the model. The applied boundary conditions used in the thermomechanical model are shown in Fig. 3.

The phase transformation is also considered in the model. The material properties of all elements reaching the AC3 temperature changed during the cooling of austenite. When austenite is cooled to the $\mathrm{M}_{\mathrm{f}}$ temperature, the material properties of the elements changed to martensite. Elements that do not reach temperature $\mathrm{ACl}$ maintain the properties of the base material. The birth and death feature was employed for all elements receiving an average temperature of $1440{ }^{\circ} \mathrm{C}$. All these elements were "killed." This elements' stiffness matrix was multiplied by a penalty factor, and all strains, including the plastic strains, were eliminated.

Two heat sources were applied to calculate the temperature for the laser hybrid welding process, the double-ellipse heat source according to Glodak [22] for the arc and the volumetric conical heat source for the laser according to [23]. The numerical simulations were performed for the welding parameter which provided an influence on the crack formations to understand the stress development and its influence on the crack formation.

\section{Results and discussion}

The X-ray images for the specimens welded under $7.2 \mathrm{~m} \mathrm{~min}^{-1}$ wire feed speed and welding speeds of $1 \mathrm{~m} \mathrm{~min}^{-1}, 1.5 \mathrm{~m} \mathrm{~min}^{-1}, 2 \mathrm{~m} \mathrm{~min}^{-1}$, and $2.5 \mathrm{~m} \mathrm{~min}^{-1}$ are shown in Fig. 4. The laser power has been adjusted to $7 \mathrm{~kW}$, $9.5 \mathrm{~kW}, 10 \mathrm{~kW}$, and $12.5 \mathrm{~kW}$, respectively. The experiments
Fig. 4 X-ray images for specimens welded at the wire feeding speed of $7.2 \mathrm{~m} \mathrm{~min}^{-1}$ and the welding speeds of $1 \mathrm{~m} \mathrm{~min}^{-1}$ (a), $1.5 \mathrm{~m} \mathrm{~min}^{-1}$ (b), $2 \mathrm{~m} \mathrm{~min}^{-1}$ (c), and $2.5 \mathrm{~m} \mathrm{~min}^{-1}$ (d)

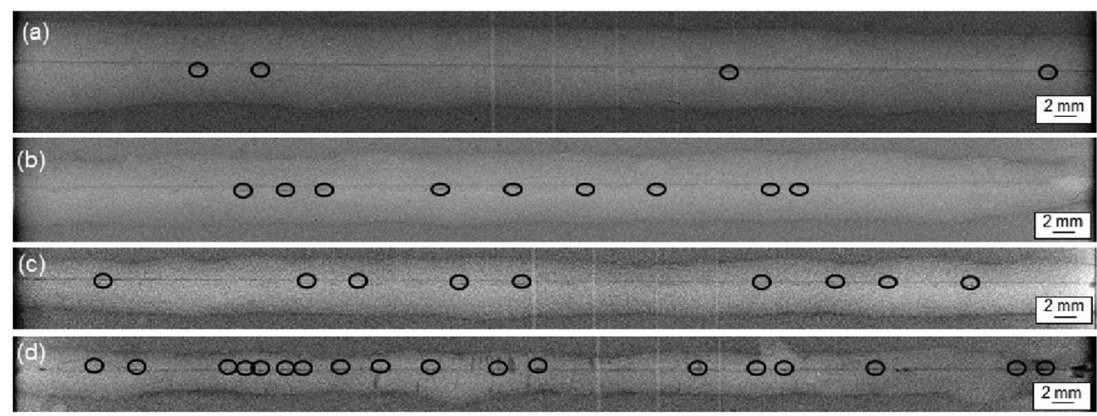


Fig. 5 Cross sections for specimens welded at the wire feeding speed of $7.2 \mathrm{~m} \mathrm{~min}^{-1}$ and the welding speeds of $1 \mathrm{~m} \mathrm{~min}^{-1}$ (a), $1.5 \mathrm{~m} \mathrm{~min}^{-1}$ (b), $2 \mathrm{~m} \mathrm{~min}^{-1}$ (c), and $2.5 \mathrm{~m} \mathrm{~min}^{-1}$ (d)

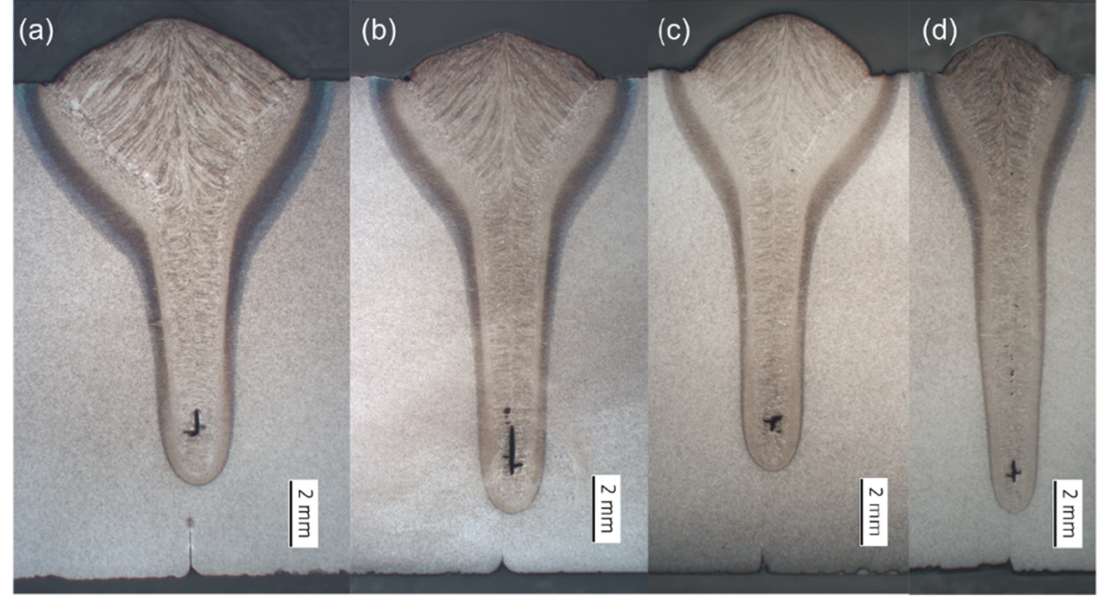

were performed with a focal position of the laser beam of $3 \mathrm{~mm}$. It can be clearly seen that the number of cracks is reduced as the welding speed decreases. The observed cracks in the X-ray images are indicated with circles.

Metallographic examinations in the form of cross sections of the welded joints are shown in Fig. 5. The cross sections were extracted at the positions, where solidification cracks were determined. The weld shapes let conclude that the welds are formed to a wine-cup shape which is typical for HLAW. The upper part is an arcdominated zone with a wide fusion zone (FZ) and heataffected zone (HAZ). The root part is the laser zone and is characterized by narrow and nearly parallel seam flanks. The width of the seam increases as the welding speed decreases due to the higher heat input. It is clearly evident that the additional power of the arc welding process has no significant influence on the root part. Cracks are formed near to the root, which is in accordance with the results by Gebhardt et al. $[15,16]$. The material separation cannot be filled with the additional filler wire.

To overcome this problem, further experiments were performed with a variation of the wire feeding speed in the range of $6.7 \mathrm{~m} \mathrm{~min}^{-1}-10.7 \mathrm{~m} \mathrm{~min}^{-1}$. The laser power was kept at $9.5 \mathrm{~kW}$ at a welding speed of $1.5 \mathrm{~m} \mathrm{~min}^{-1}$. The X-ray images are shown in Fig. 6. It is evident that the arc power has a slight influence on the crack formation. Although the number of the cracks was reduced by an increase of the wire feed speed from $6.7 \mathrm{~m} \mathrm{~min}^{-1}$ to $7.2 \mathrm{~m} \mathrm{~min}^{-1}$, beyond that, the number of hot cracks remains at the same level. There is a tendency that the arc power has a slight influence on the solidification cracks, but not quite as pronounced as that by Gebhardt et al. [15, $16]$.

The cross sections are shown in Fig. 7. An increase of the wire feed speed leads to an increase of the width of the FZ in the upper part and the root reinforcement. The depth, where the arc welding process has an influence, remains unchanged. From a penetration depth of approx. $4 \mathrm{~mm}$, narrow and nearly parallel seam flanks can be seen.

Figure 8a summarizes the dependence of the number of cracks on the wire feeding speed and the welding speed in Fig. 8 b. As it is stated above, the number of cracks is slightly reduced as the wire feed speed increases.

It can be clearly seen that by increasing the wire feeding speed from $8.7 \mathrm{~m} \mathrm{~min}^{-1}$ to $10.7 \mathrm{~m} \mathrm{~min}^{-1}$, the number of cracks remains approximately the same. It must be mentioned here
Fig. 6 X-ray images for specimens welded with a laser power of $9.5 \mathrm{~kW}$ at a welding speed of $1.5 \mathrm{~m} \mathrm{~min}^{-1}$ and wire feed speeds of $6.7 \mathrm{~m} \mathrm{~min}^{-1}$ (a), $7.2 \mathrm{~m} \mathrm{~min}^{-1}$ (b), $7.7 \mathrm{~m} \mathrm{~min}^{-1}$ (c), $8.7 \mathrm{~m} \mathrm{~min}^{-1}(\mathbf{d})$, and $10.7 \mathrm{~m} \mathrm{~min}^{-1}(\mathbf{e})$

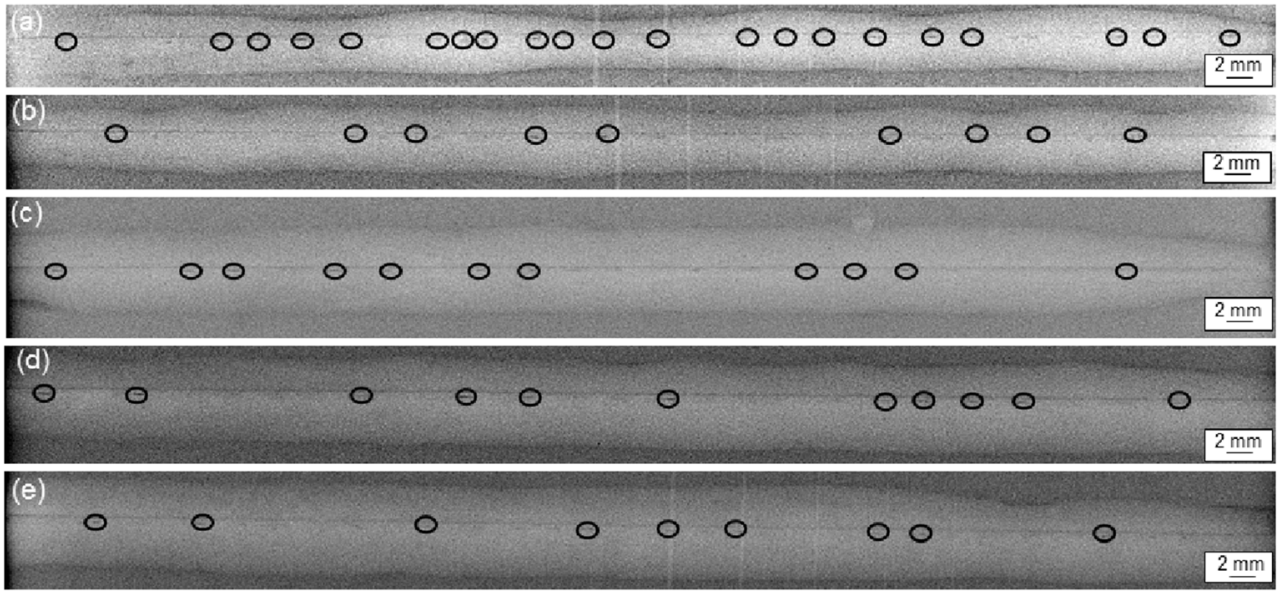




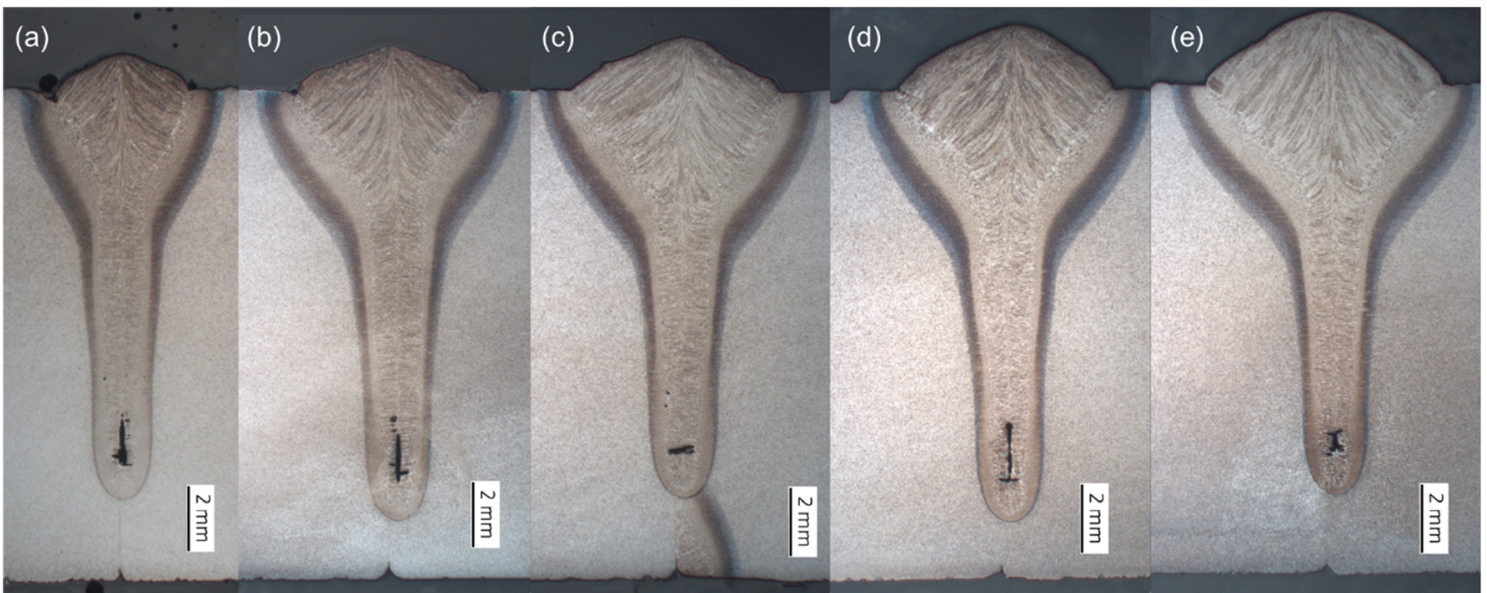

Fig. 7 Cross sections for specimens welded with a laser power of $9.5 \mathrm{~kW}$ at a welding speed of $1.5 \mathrm{~m} \mathrm{~min}^{-1}$ and wire feed speeds of $6.7 \mathrm{~m} \mathrm{~min}{ }^{-1}$ (a), $7.2 \mathrm{~m} \mathrm{~min}^{-1}(\mathbf{b}), 7.7 \mathrm{~m} \mathrm{~min}^{-1}(\mathbf{c}), 8.7 \mathrm{~m} \mathrm{~min}^{-1}(\mathbf{d})$, and $10.7 \mathrm{~m} \mathrm{~min}^{-1}(\mathbf{e})$

that the influence of the arc power on the crack formation depends strongly also on the welding depth. The results by varying the welding speed have provided clearer evidence of its influence on the cracking phenomena. In Fig. 8b, the number of cracks increases as the welding speed increases.

The influence of the focal position of the laser beam was also examined. Figure 9 shows the X-ray images for specimens welded with different focal positions for two different welding speeds. Figure $9 \mathrm{a}-\mathrm{c}$ shows results for welded joints with a welding speed of $1.5 \mathrm{~m} \mathrm{~min}^{-1}$, whereas Fig. 9d-f for $1 \mathrm{~m} \mathrm{~min}^{-1}$, respectively. For the higher welding speed, it can be clearly seen that a focal position of $0 \mathrm{~mm}$ leads to a reduction of the number of cracks.

For both welding speeds $\left(1.5 \mathrm{~m} \mathrm{~min}^{-1}\right.$ and $\left.1 \mathrm{~m} \mathrm{~min}^{-1}\right)$, a significant increase of cracks has been observed at a focal position of $-6 \mathrm{~mm}$, whereas a significant reduction of the number of the cracks can be observed at the focal position of $0 \mathrm{~mm}$. The influence of the welding speed and the focal position on the crack formation in the weld root is summarized in Fig. 10.
The positive effect of reducing the welding speed and reducing the focal position from the specimen surface can be clearly recognized. That is by reducing the welding speed and focusing the laser on the specimen surface, the crack number has been significantly reduced.

To clarify the influence of the welding speed, numerical simulations were performed, since that factor showed the greatest impact on the solidification cracks at partially penetrated HLAW joints.

Numerical simulations were performed for the welding speeds of $1 \mathrm{~m} \mathrm{~min}^{-1}$ and $2 \mathrm{~m} \mathrm{~min}^{-1}$, where a clear impact on the number of cracks can be observed. The heat source parameters, which were used for thermal analyses, were optimized to achieve a good match between the experiments and the model. These parameters were adjusted until an error of less than $5 \%$ was obtained.

Figure 11a shows the weld geometry comparison between the numerical and the experimental cross sections after the calibration, and Fig. $11 \mathrm{~b}$ shows the temperature measurements over time using thermocouples on the top and the bottom surfaces of the specimen compared with those obtained from
Fig. 8 Results of the number of the cracks under variation of the wire feed speed (a) and the welding speed (b) with a standard deviation

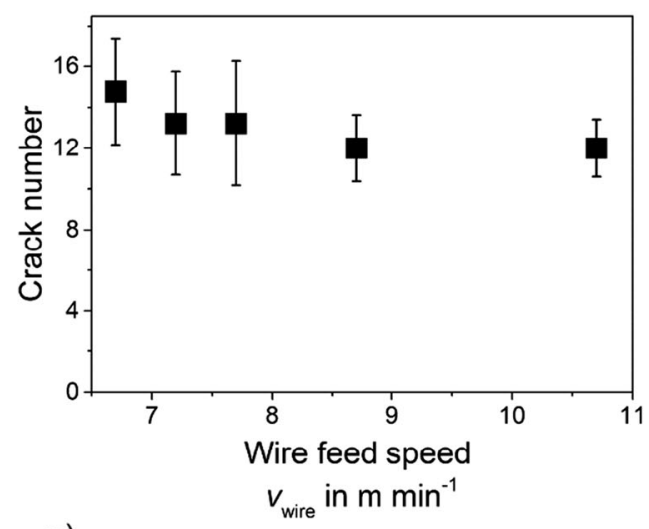

a)

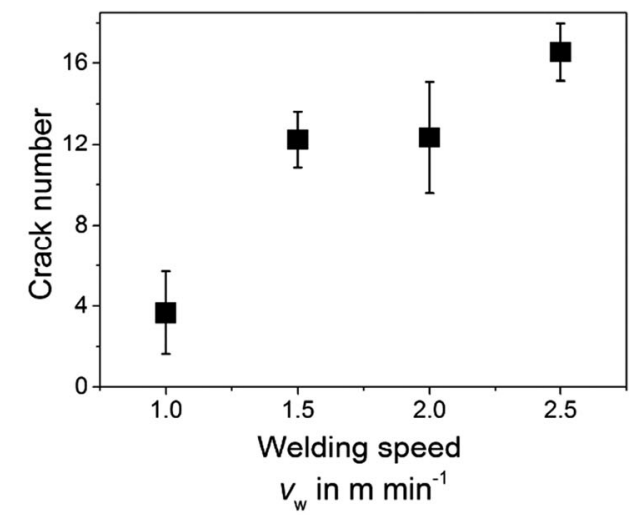

b) 

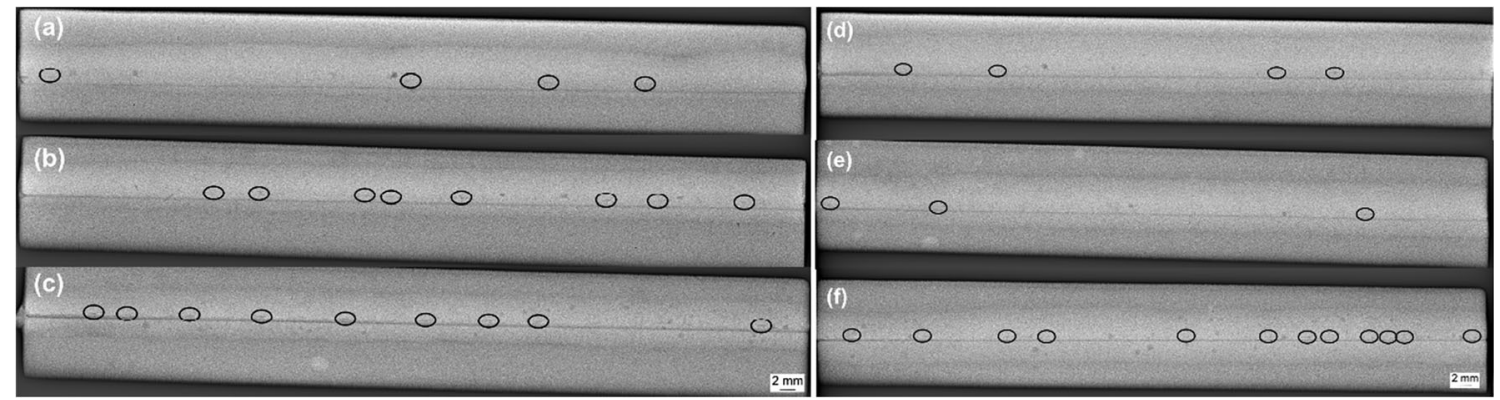

Fig. 9 X-ray images for specimens welded with a focal position of $0 \mathrm{~mm}(\mathbf{a}),-3 \mathrm{~mm}(\mathbf{b}),-6 \mathrm{~mm}(\mathbf{c})$ at a welding speed of $1.5 \mathrm{~m} \mathrm{~min}{ }^{-1} ; 0 \mathrm{~mm}(\mathbf{d}),-$ $3 \mathrm{~mm}(\mathbf{e})$, and $-6 \mathrm{~mm}(\mathbf{f})$ at a welding speed of $1 \mathrm{~m} \mathrm{~min}^{-1}$

calculations. The other numerical simulations were based on the validated model by changing the welding parameters.

The transversal and vertical stress distributions for a specimen welded with $2 \mathrm{~m} \mathrm{~min}^{-1}$ are shown in Fig. 12. A concentration of stress at the root of the weld can be observed. As

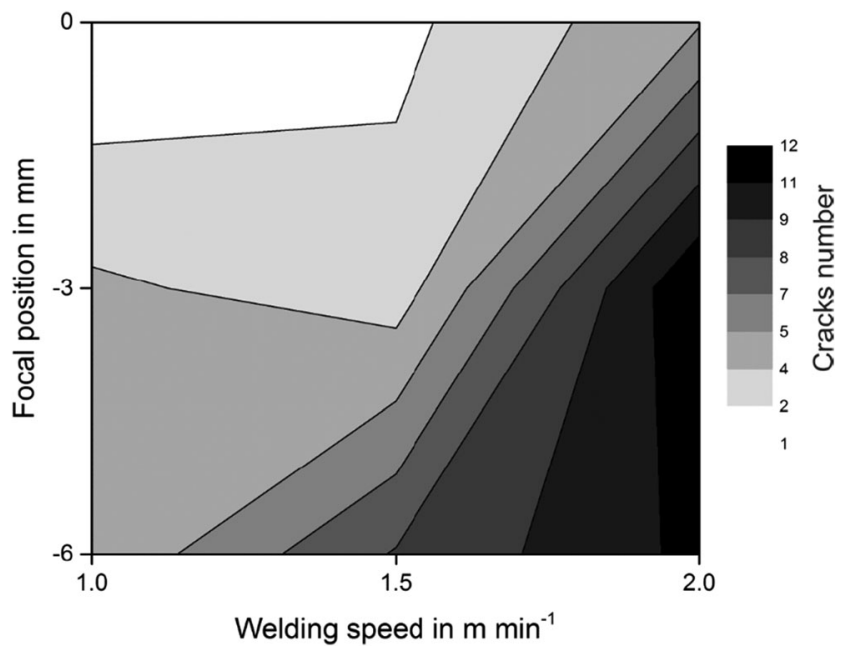

Fig. 10 Results of the number of cracks under the variation of the welding speed and the focal position

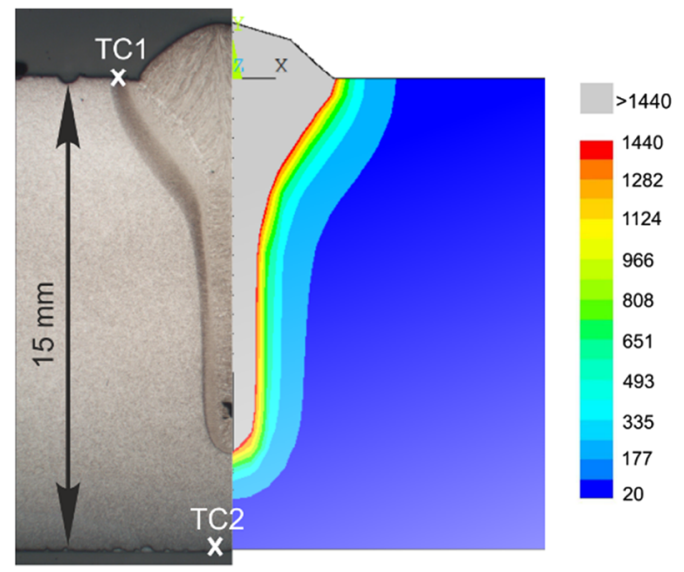

a) demonstrated by the numerical model, this concentration of stress arises in the same place as experimentally detected solidification cracks (see Fig. 13).

This tensile stress concentration at the weld root immediately after the solidification is critical for solidification cracking phenomena where interdendritic liquid remains, as reported by Zacharia [12].

The transversal and vertical stress evolution versus the temperature during cooling at the location of the crack in the weld root is shown in Fig. 14. Transversal and vertical tensile stress development could be observed immediately after solidification, continuing to rise until reaching a value of $80 \mathrm{MPa}$ and $110 \mathrm{MPa}$, respectively. The high tensile stress in the weld root can be attributed to the thermal stress (after solidification) and the restraint to shrinkage by the surrounding cold material.

This explains the usual crack form in the weld root having either a horizontal (Fig. 15a) or vertical orientation (Fig. 15b) or taking the shape of a cross under the influence of both stress components (Fig. 15c).

Figure 16 shows the stress development on the locations of the cracks for specimens welded with $2 \mathrm{~m} \mathrm{~min}^{-1}$ and $1 \mathrm{~m} \mathrm{~min}^{-1}$ over the temperature. By comparison of the stress development for the two welding speeds at the weld root, a

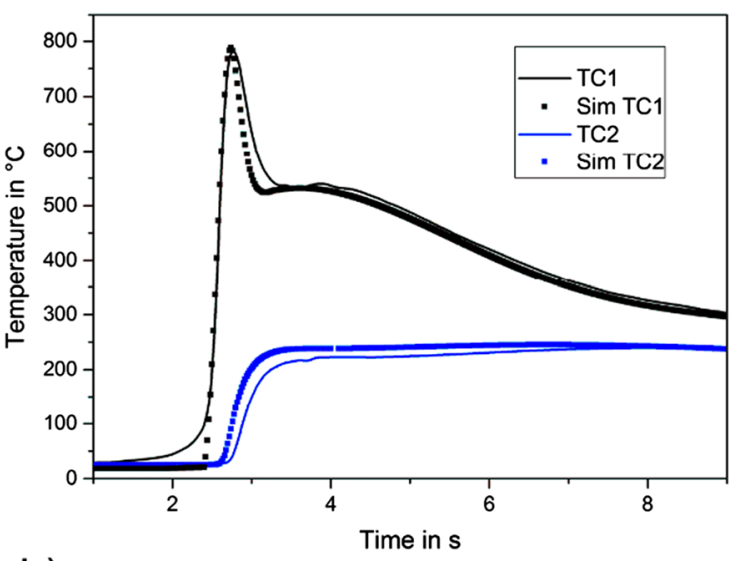

b)

Fig. 11 Comparison of experimental and numerical weld cross section (a). Comparison of the temperature cycles between experiments and the computational model (b) 
Fig. 12 Transversal (a) and vertical (b) stress distribution and temperature distribution during solidification of the weld pool

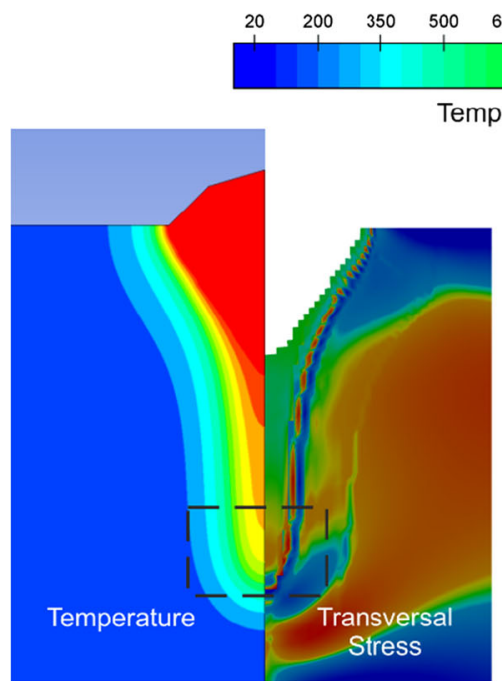

a)

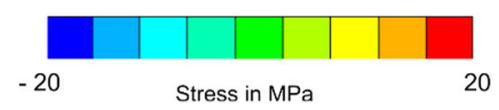

reduction of the stress can be recognized. This reduction in the stresses is due to the increase of the width of the weld pool and the heat-affected zone (HAZ). The stress is reduced due to the reduction of the restraint to shrinkage by the surrounding cold material if the weld pool and HAZ in the laser-dominated area is getting wider as a result of the decrease of the welding speed.
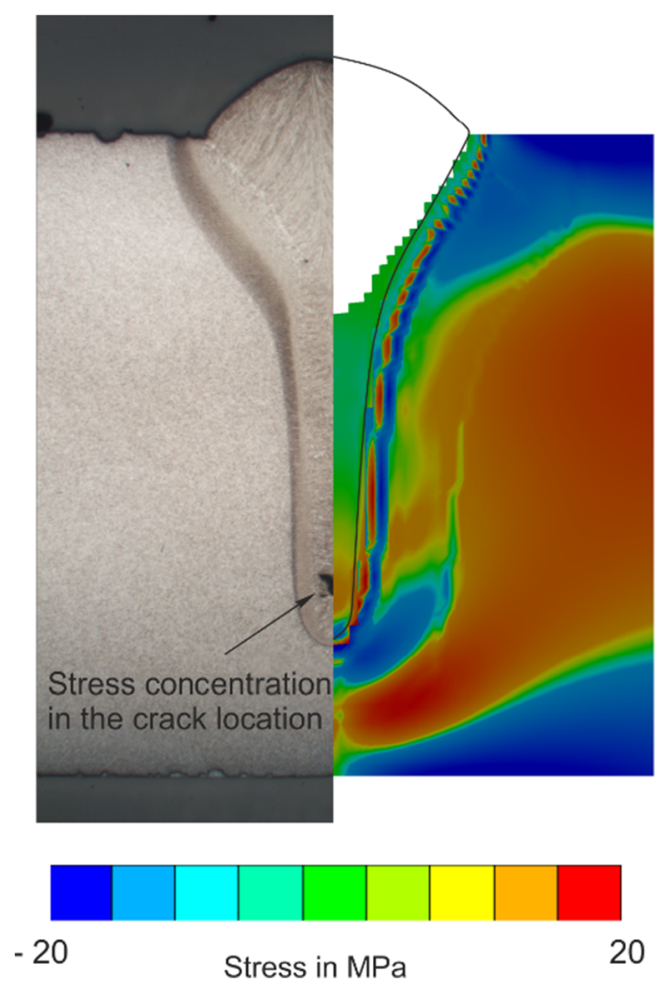

Fig. 13 Transversal stress distribution during solidification of the weld pool compared with the cross section and the crack location
In addition to the stress, the shape of the weld pool in the laser-dominated area plays a significant role in solidification cracking in the weld root.

Figure 17 shows the cross section for two specimens welded with $1.5 \mathrm{~m} \mathrm{~min}^{-1}$ (a) and $1 \mathrm{~m} \mathrm{~min}^{-1}$ (b). The overlap of the two fusion lines taken from the cross sections are shown in Fig. 17c. The angle between the fusion line and the vertical line refers to the mechanism of the solidification. Here, it can be seen that the width of the seam increases significantly with the reduction of the welding speed. In addition to the expansion of the seam, it can be recognized that the seam flanks do not run parallel at the welding speed of $1 \mathrm{~m} \mathrm{~min}^{-1}$. The angle of the seam flanks opens strongly in the laser-dominated zone. For the other specimen, the seam flanks are parallel in this area. The parallel seam flanks promote hot cracking [24]. Due to the parallel melting fusion lines, low-melting eutectics, such as iron sulfide (FeS), accumulate in the middle of the seam. This metallurgical factor, i.e., low-melting eutectics between the two solidification fronts in the weld root (see Fig. 18b), is normally an undesirable contribution to

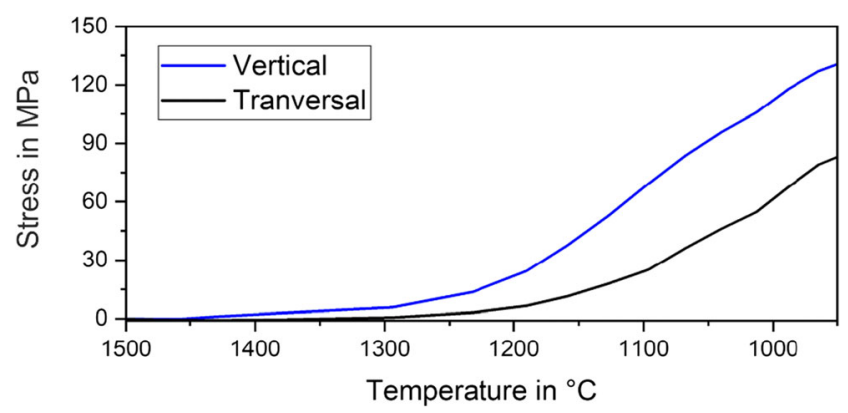

Fig. 14 The vertical and the transversal stress development at the weld root 
Fig. 15 Solidification crack forms in the weld root horizontal (a), vertical (b), and cross-shaped cracks (c)

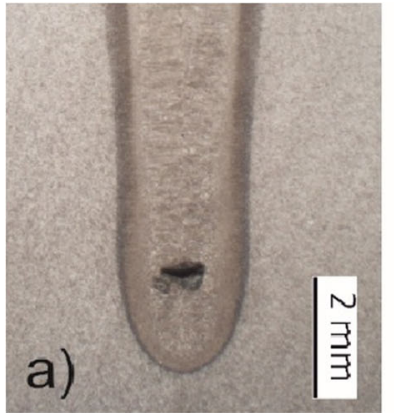

b)
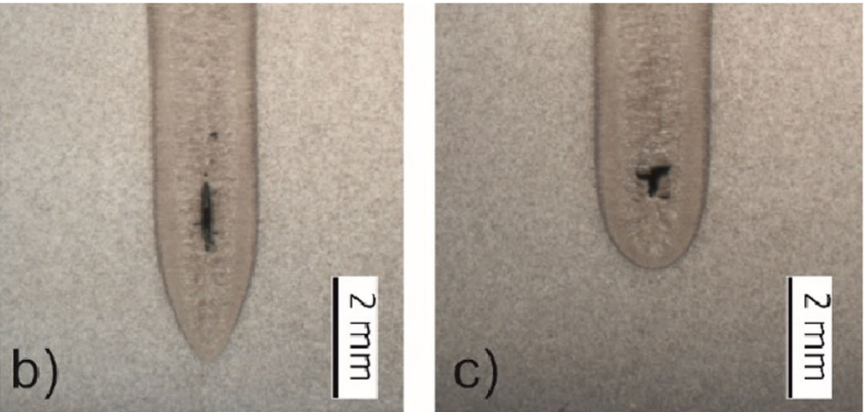

solidification cracking $[8,25,26]$. The larger the flank angle of the weld, the more impurities can be brought to the surface of the weld bead. Welds with a wide width-to-depth ratio would favor this effect. The schematic solidification of a weld with a small width-to-depth ratio and a weld with a large width-to-depth ratio is shown in Fig. 18. This figure also shows where the impurities would collect.

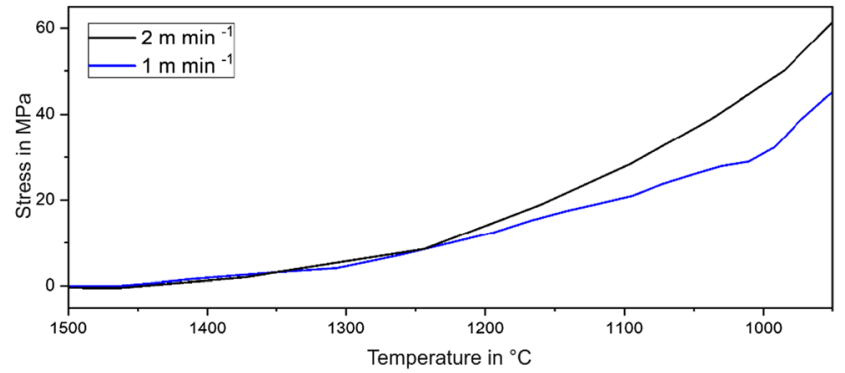

Fig. 16 Transversal stress development for specimens modeled with welding speed of $1 \mathrm{~m} \mathrm{~min}^{-1}$ and $2 \mathrm{~m} \mathrm{~min}^{-1}$ at the weld root

\section{Conclusion}

In this study, the influence of the welding speed, the arc power, and the laser focal position on the solidification crack formation for partial penetration laser hybrid-welded thickwalled plates was investigated.

The solidification cracking in the weld root is a result of interaction between metallurgical and geometrical and thermomechanical factors.

Experimentally, a direct correlation between the welding speed and the crack number was observed. That is by reducing the welding velocity, the crack number was decreased. The focal position shows also a significant influence on the crack number. By focusing the laser on the specimen surface, the crack number has been significantly diminished.

The wire feed speed showed a very slight influence on the crack formation. That is due to the large distance between the critical region for cracking and the arc region.

The numerical model shows a high stress concentration in the weld root for both components (vertical and transversal).

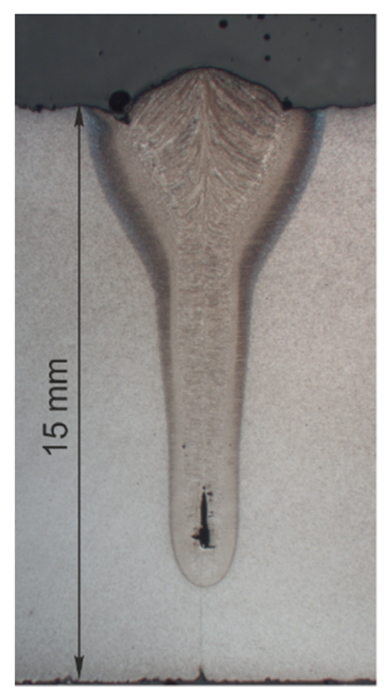

a)

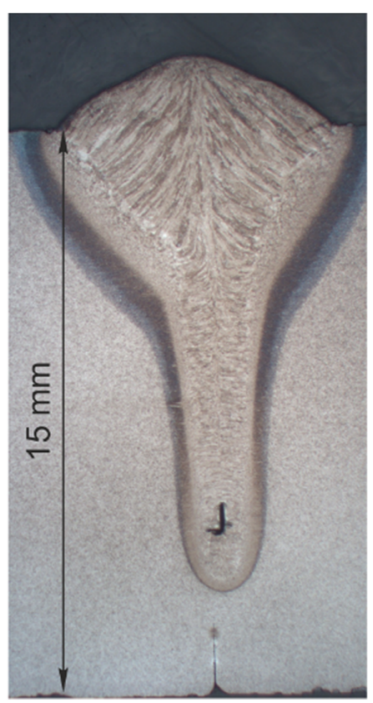

b)

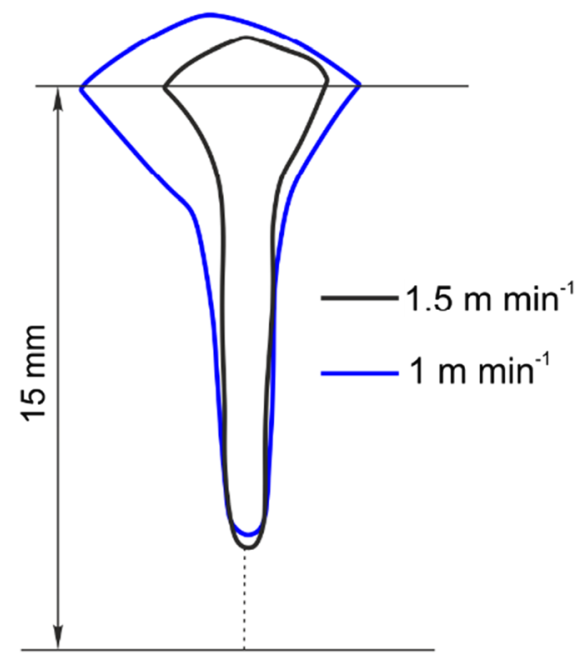

c)
Fig. 17 Cross sections for specimens welded with a laser power of $9.5 \mathrm{~kW}$ at a welding speed of $1.5 \mathrm{~m} \mathrm{~min}^{-1}$ and a wire feed speed of $6.7 \mathrm{~m} \mathrm{~min}^{-1}$ (a) and for specimens welded with a laser power of $7 \mathrm{~kW}$ at a welding speed of $1 \mathrm{~m} \mathrm{~min}^{-1}$ and wire feed speeds of $7.2 \mathrm{~m} \mathrm{~min}^{-1}$ (b), (c) comparison between the two cross sections 


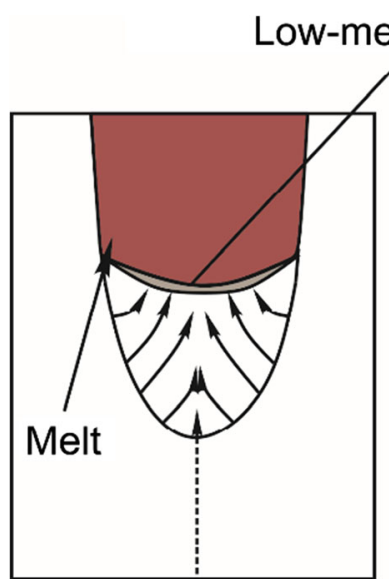

a)

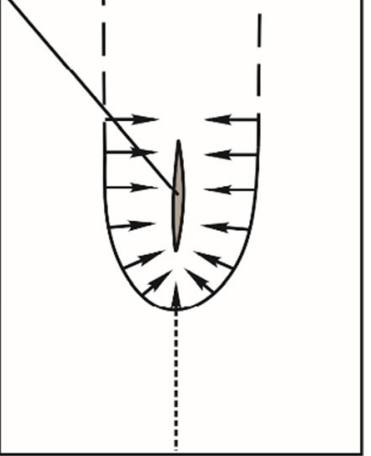

b)
Fig. 18 Schematic representation of a weld in the weld root with nonparallel (a) and parallel (b) fusion lines; the direction of solidification is indicated by the arrows, adapted from [19]

Numerically, the reduced welding speed showed a strong impact on stress, as the model demonstrated a lower stress amount by decreasing the welding speed.

The metallurgical factors, such as the assumed accumulation of the low-melting eutectics in the weld root, should be a contribution for solidification cracking, where the tensile stress is acting.

Funding information Open Access funding provided by Projekt DEAL. This work was supported by the Research Association for Steel Application (FOSTA), the Federation of Industrial Research Associations (AiF), and the German Federal Ministry for Economic Affairs and Energy (BMWi Bundesministerium für Wirtschaft und Energie) (Project 19582N, "Investigation of the influence the restraint conditions on hot cracking in laser and laser-hybrid welding of thick structure steels").

Open Access This article is licensed under a Creative Commons Attribution 4.0 International License, which permits use, sharing, adaptation, distribution and reproduction in any medium or format, as long as you give appropriate credit to the original author(s) and the source, provide a link to the Creative Commons licence, and indicate if changes were made. The images or other third party material in this article are included in the article's Creative Commons licence, unless indicated otherwise in a credit line to the material. If material is not included in the article's Creative Commons licence and your intended use is not permitted by statutory regulation or exceeds the permitted use, you will need to obtain permission directly from the copyright holder. To view a copy of this licence, visit http://creativecommons.org/licenses/by/4.0/.

\section{References}

1. Steen WM, Eboo M, Clarke J (1978) Arc augmented laser welding of materials In: Advances in Welding Processes Proceedings, 4th International Conference
2. Gumenyuk A, Rethmeier M (2013). Developments in hybrid laserarc welding technology. In Handbook of laser welding technologies, pp. 505-521

3. Jasnau U, Hoffmann J, Seyffarth P (2002) Nd: YAG-laser-gas metal arc-hybrid welding: a chance for the use of the advantages of laser technology and flexible automation in shipbuilding and steel construction. In: Proceeding of the International Conference on Robotic Welding, Intelligence and Automation, Shanghai, pp 9-12

4. Roland F, Manzon L, Kujala P, Brede M, Weitzenböck J (2004) Advanced joining techniques in European shipbuilding. J Ship Prod 20(3):200-210

5. Churiaque C, Chludzinski M, Porrua-Lara M, Dominguez-Abecia A, Abad-Fraga F, Sánchez-Amaya JM (2019) Laser hybrid butt welding of large thickness naval steel. Metals 9(1):100

6. Cross CE, Coniglio N (2008) Weld solidification cracking: critical conditions for crack initiation and growth. In: Heidelberg SB (ed) Hot Cracking Phenomena in Welds II, pp 39-57

7. Apblett WR, Pellini WS (1954) Factors which influence weld Hot cracking. Weld Res Suppl 33:83-90

8. Cross CE (2005) On the origin of weld solidification cracking. In: Hot Cracking Phenomena in Welds, pp 3-18

9. Prokhorov NN, Gavrilyuk MN (1971) Strain behavior of metals during solidification after welding. Svar Proiz 18(6):5-9

10. Prokhorov NN (1956) The problem of the strength of metals while solidifying during welding. Svar Proizvod 6:5-11

11. Prokhorov NN (1962) The technological strength of metals while crystallising during welding. Svar Proiz 4:1-8

12. Zacharia T (1994) Dynamic stresses in weld metal hot cracking. Weld Res Suppl 73(July):164-172

13. Feurer U (1977) Influence of alloy composition and solidification conditions on dendrite arm spacing, feeding and hot tearing properties of aluminium alloys. In: International Symposium on Engineering Alloys, pp. 131-145

14. Bakir N, Artinov A, Gumenyuk A, Bachmann M, Rethmeier M (2018) Numerical simulation on the origin of solidification cracking in laser welded thick-walled structures. Metals 8(6):406

15. Gebhardt MO, Gumenyuk A, Rethmeier M (Dec. 2013) Numerical analysis of hot cracking in laser-hybrid welded tubes. Adv Mater Sci Eng 2013:1-8

16. Gebhardt MO, Gumenyuk A, Rethmeier M (2014) Solidification cracking in laser GMA hybrid welding of thick-walled parts. Sci Technol Weld Join 19(3):209-213

17. Schaefer M, Kessler S, Scheible P, Speker N, Harrer T (2017) Hot cracking during laser welding of steel: influence of the welding parameters and prevention of cracks. In: High-Power Laser Materials Processing: Applications, Diagnostics, and Systems VI, vol 10097, p 100970E

18. Schaefer M, Kessler S, Fetzer F, Graf T (2017) Influence of the focal position on the melt flow during laser welding of steel. $J$ Laser Appl 29(1):12010

19. Bakir N, Gumenyuk A, Rethmeier M (Sep. 2016) Numerical simulation of solidification crack formation during laser beam welding of austenitic stainless steels under external load. Weld World 60(5): $1001-1008$

20. ESI Group (2009) Material database

21. Gebhardt M, Quiroz V, Gumenyuk A, Rethmeier M (2009) Restraint effects on stresses and strains in single-pass, high power laser beam welding of thick plates. In: Mathematical Modelling of weld phenomena

22. Goldak J, Chakravarti A, Bibby M (1984) A new finite element model for welding heat sources. Metall Trans B 15(June):299-305 
23. Wu CS, Wang HG, Zhang YM (2006) A new heat source model for keyhole plasma arc welding in FEM analysis of the temperature profile. Weld Res 85(12):284

24. Schuster J (2004) Heißrisse in Schweißverbindungen - Entstehung, Nachweis und Vermeidung, DVS-Berich. DVS-Verlag, Düsseldorf

25. Quiroz V, Gebhardt M, Gook S (2010) Hot cracking in high power laser beam welding of thick high strength structural steels under restraint conditions. In: ICALEO 2010 - 29th International Congress on Applications of Lasers \& Electro-Optics, pp 225-232
26. Artinov A, Bakir N, Bachmann M, Gumenyuk A, Na S-J, Rethmeier M (2019) On the search for the origin of the bulge effect in high power laser beam welding. J Laser Appl 31(2):022413

Publisher's note Springer Nature remains neutral with regard to jurisdictional claims in published maps and institutional affiliations. 